\title{
Taming the First-Order Transition in Giant Magnetocaloric Materials
}

\author{
François Guillou,* Giacomo Porcari, Hargen Yibole, Niels van Dijk, and Ekkes Brück
}

The change in temperature resulting from a change in the magnetic field applied to a magnetic material is called the magnetocaloric effect (MCE). Integrating this effect into a thermodynamic cycle could lead to a broad range of applications. One of the most attractive is magnetic refrigeration at room temperature. This cooling technique offers the possibility of advantageously replacing the conventional vapor-compression technology since it has a higher efficiency and does not use refrigerant gases that are greenhouse gases..$^{[1,2]}$ The search for magnetic materials displaying a large MCE is the first step in its development and is nowadays very active. More precisely, since the discovery of "giant" MCE (G-MCE), which occurs when the latent heat of a first-order transition (FOT) is involved, ${ }^{[3]}$ research has focused on reaching ever stronger magnetic FOTs, that is to say, on reaching the largest latent heat possible, and the strongest magneto-structural coupling (e.g., cell-volume change at the FOT). ${ }^{[4]}$ However, though this approach is beneficial for reaching high MCE performances, in particular large entropy changes, it is accompanied by definite drawbacks, such as pronounced hysteretic phenomena, irreversibility of the effect, or poor mechanical stability. Here we report how a totally different approach has been used to design new materials displaying a unique combination of intense MCE and several practical advantages (based on 3d elements, limited hysteresis, no volume change at the transition), making them highly suitable for magnetic refrigeration. In $\mathrm{MnFe}(\mathrm{P}, \mathrm{Si}, \mathrm{B})$ compounds, large adiabatic temperature changes of $2.5 \mathrm{~K}$ and entropy changes of about $10 \mathrm{~J} \mathrm{~kg}^{-1} \mathrm{~K}^{-1}$ are achieved for a moderate field variation (1 T), while the reversibility of the effect and the mechanical stability of the samples are ensured. These results are supported by extensive experimental work combining different direct and indirect characterization methods.

The highest MCEs reported in recent years have been found in various families of intermetallic compounds: $\mathrm{Gd}_{5}(\mathrm{Ge}, \mathrm{Si})_{4}{ }^{; 3]}$ $\mathrm{Mn}(\mathrm{As}, \mathrm{Sb}) ;{ }^{[5]} \mathrm{La}(\mathrm{Fe}, \mathrm{Si})_{13}$ and its hydrides; $;^{[6,7]} \mathrm{Mn}_{2-\gamma} \mathrm{Fe}_{\gamma}(\mathrm{P}, x)$, where $x=\mathrm{As}, \mathrm{Ge}, \mathrm{Si} ;{ }^{[8-11]}$ Heusler alloys Ni-Mn- $X(X=\mathrm{Ga}, \mathrm{Sn}$, In,...); $;^{[12-16]} \mathrm{MnCoGe} ;{ }^{[17]}$ and some other compounds. ${ }^{[1,2]}$ All these G-MCE materials show large entropy-change $(\Delta S)$ values. However, a point too often neglected in the field of G-MCE materials,

Dr. F. Guillou, H. Yibole, Dr. N. van Dijk, Dr. E. Brück Fundamental Aspects of Materials and Energy (FAME) Delft University of Technology

Mekelweg 15, 2629 JB Delft, The Netherlands

E-mail: f.guillou@tudelft.nl

Dr. G. Porcari

Department of Physics and Earth Sciences

University of Parma

Viale G.P Usberti n.7/A (Parco Area delle Scienze),43124 Parma, Italy

DOI: 10.1002/adma.201304788 even though these compounds are most prone to such drawbacks, is the negative role of hysteresis. Since all MCE applications have a cyclic character, one of the main pre-conditions is to ensure a total (or at least partial) reversibility of the effect when either field or temperature oscillations are applied. From a material point of view, this means keeping the field or thermal hysteresis that could occur as small as possible. A second drawback of G-MCE materials is related to their mechanical stability. FOTs bring not only sharp magnetization jumps but also discontinuities of other physical parameters, including the unit cell. This "structural" part can have manifold aspects: symmetry breaking or cell-volume or lattice-parameter changes. The most dramatic for the stability of polycrystalline bulk samples turns out to be the cell-volume change. During thermal or magnetic field cycles, the strains generated by a volume change may cause fractures or even destruction of the bulk piece, which severely hinders the applicability of these materials. Technical solutions can be used to overcome this problem, for instance by embedding the MCE material in a resin or by a porous shaping. ${ }^{[18]}$ However, in such cases the MCE is "diluted", which is not satisfactory since the gap of the magnet is not efficiently used and the thermal conductivity governing the heat transfer is decreased. Bulk G-MCE materials with a good mechanical stability should remain the preferred solution. Finally, to allow large-scale applications, a last requirement that should be borne in mind is that the MCE material must consist of elements that are available in large amounts, are not expensive, and are not classified as toxic.

In this context, the $\operatorname{MnFe}(\mathrm{P}, x)$ system appears to be an ideal playground. This material family is derived from the $\mathrm{Fe}_{2} \mathrm{P}$ compound, a prototypical example known for a long time to exhibit a sharp but weak (the latent heat $L$ is only $0.25 \mathrm{~kJ} \mathrm{~kg}^{-1}$ ) FOT with a Curie temperature $\left(T_{\mathrm{C}}\right)$ of $217 \mathrm{~K} \cdot{ }^{[19]}$ In this hexagonal system, the Fe atoms occupy two inequivalent atomic positions referred to as $3 \mathrm{f}$ (in a tetrahedral environment of non-metallic atoms) and $3 \mathrm{~g}$ (pyramidal). An intriguing aspect is the disappearance at $T_{C}$ of the magnetic moments of the iron atoms at the $3 \mathrm{f}$ sites, whereas there is only a limited decrease of the moments at the $3 \mathrm{~g}$ site. This theoretical prediction has led to a cooperative description of the FOT that links the loss of longrange magnetic order at $T_{\mathrm{C}}$ with the loss of the local moments at the $3 \mathrm{f}$ site. ${ }^{[20]}$ This mechanism has recently been proposed to be the origin of the G-MCE observed in $\operatorname{MnFe}(\mathrm{P}, \mathrm{Si})$. The disappearance of the magnetic moments is ascribed to a conversion from non-bonding $d$ electrons to a distribution with pronounced hybridization with the surrounding $\mathrm{Si} / \mathrm{P}$ atoms. ${ }^{[11]}$ A practical consequence is that the FOT mechanism can be expected to be highly sensitive to substitutions at the nonmetallic site. In the present work, precisely this approach has been used to solve three problems of the previous generation of $\mathrm{MnFe}(\mathrm{P}, \mathrm{Si})$ materials. 1) The first improvement needed is 
related to the enhancement of the adiabatic temperature change $\left(\Delta T_{\text {ad }}\right)$. For magnetic-refrigeration applications, it is of primary interest to optimize the heart of the device, the MCE material. This MCE is quantified either by the entropy change $(\Delta S)$ or by $\Delta T_{\text {ad }}$, depending on whether the magnetic-field change is performed isothermally or adiabatically. Comparing different materials reveals that a large $\Delta S$ does not necessarily imply a large $\Delta T_{\mathrm{ad}}$, and vice versa; both quantities have to be optimized simultaneously. This is an unsatisfactory point for $\mathrm{MnFe}(\mathrm{P}, \mathrm{Si})$ materials, which exhibit large $\Delta S$ but limited $\Delta T_{\text {ad }}(\sim 2 \mathrm{~K}$ in $1 \mathrm{~T})$. 2) The second target is to solve the mechanical stability problem observed in $\mathrm{MnFe}(\mathrm{P}, \mathrm{Si})$. Even though the cell-volume change of these materials at the FOT is limited $(\Delta V=+0.2 \%),{ }^{[21]}$ crossing the transition still leads to fractures or destruction of bulk samples. 3) The last objective is to provide materials having a large MCE at intermediate fields, that is, at those offered by permanent magnets. If the magnetic field required to fully induce the FOT is considerably higher than the field source of the magnetic refrigerator (which is often the case for a FOT with large $L$ ), the material is designed in an inefficient way, since all the drawbacks of a FOT are present but only a part of the transition is really used. A good strategy to incorporate most of the latent heat into the MCE is to optimize the temperature shift of the transition due to the applied field.

Based on the Clausius-Clapeyron description $\mathrm{d}_{\mathrm{C}} / \mathrm{d} B=-T_{\mathrm{C}} \Delta M / L$, where $B$ is the magnetic flux density and $\Delta M$ the jump in magnetization, the optimizations (1) and (3) above imply that $d T_{C} / d B$ should be increased, that is, an increase of $\Delta M$ and decrease of the latent heat. In earlier studies of $\mathrm{MnFe}(\mathrm{P}, \mathrm{Si})$ materials, reduction of the hysteresis was achieved by adjustment of the $\mathrm{Mn} / \mathrm{Fe}$ and $\mathrm{P} / \mathrm{Si}$ ratios, which, unfortunately, reduces the magnetization. To increase the magnetization and $\Delta M$, it is required to work around the $\mathrm{MnFeP}_{2 / 3} \mathrm{Si}_{1 / 3}$ composition, which is a double optimum for the saturation magnetization, $\mathrm{Mn} / \mathrm{Fe} \sim 1$ and $\mathrm{Si} \sim 1 / 3 .{ }^{[21,22]} \mathrm{To}$ control the latent heat, however, a new ingredient is required,

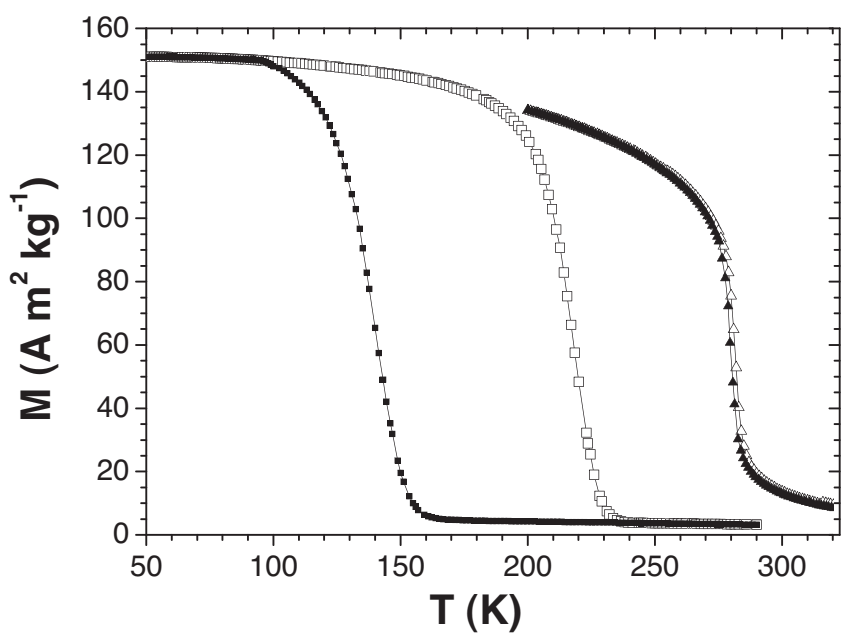

Figure 1. Temperature dependence of the magnetization in the parent compound and in a boron-substituted material. Isofield magnetization curves recorded at $B=1 \mathrm{~T}$ upon cooling (filled symbols) and upon heating (open symbols) for $\mathrm{MnFe}_{0.95} \mathrm{P}_{0.67} \mathrm{Si}_{0.33}$ (squares) and $\mathrm{MnFe}_{0.95} \mathrm{P}_{0.595} \mathrm{~B}_{0.075} \mathrm{Si}_{0.33}$ (triangles). a parameter able to decrease the latent heat while keeping the magnetization unmodified. For this purpose, boron substitution at the non-magnetic site (replacement of P by B) has been investigated.

In $\mathrm{MnFe}(\mathrm{P}, \mathrm{Si})$ materials, the effect of $\mathrm{B}$ substitution on $T_{\mathrm{C}}$ is similar to that in $\mathrm{Fe}_{2} \mathrm{P}^{\left[{ }^{[23]}\right.}$ On the isofield $M_{\mathrm{B}}(T)$ curves, Figure 1, starting from the "magnetization optimum" $\mathrm{MnFe}_{0.95} \mathrm{P}_{2 / 3} \mathrm{Si}_{1 / 3}$, substitution of $\mathrm{B}$ for $0.075 \mathrm{P}\left(\mathrm{MnFe}_{0.95} \mathrm{P}_{0.595} \mathrm{~B}_{0.075} \mathrm{Si}_{0.33}\right)$ leads to a significant increase of $T_{C}$ (for $T_{C}$ measured upon heating from $215 \mathrm{~K}$ to $283 \mathrm{~K}$; see the Supporting Information S1 for intermediate compositions). Most interesting is the fact that the extremely large difference between heating and cooling Curie temperatures of the parent compound $\mathrm{MnFe}_{0.95} \mathrm{P}_{2 / 3} \mathrm{Si}_{1 / 3}$ (thermal hysteresis of $75 \mathrm{~K}$ ) is strongly suppressed by $\mathrm{B}$ substitution, resulting in a hysteresis of only $1.6 \mathrm{~K}$ in the $\mathrm{B}=7.5 \%$ compound. The average hysteresis decrease by $\mathrm{B}$ doping is about $10 \mathrm{~K}$ per percent $\mathrm{B}$, a value much higher than obtained by changing the $\mathrm{Mn} / \mathrm{Fe}$ ratio $(-1.2 \mathrm{~K}$ per $\mathrm{Mn}$ or $\mathrm{Fe} \%$ ) or the $\mathrm{P} /$ Si ratio $(-1.1 \mathrm{~K}$ per Si\%). Moreover, since the control of the hysteresis is now achieved without deviating from the $\mathrm{Mn} / \mathrm{Fe} \sim 1$ and $\mathrm{Si} \sim 1 / 3$ optima, the magnetization in the ferromagnetic state far below $T_{\mathrm{C}}$ is kept unmodified (the two samples exhibit a magnetization of $150 \mathrm{~A} \mathrm{~m}^{2} \mathrm{~kg}^{-1}$ at $50 \mathrm{~K}$ ), which is very important for the MCE performance.

The MCE evaluation of a new material requires a complete characterization of both $\Delta S$ and $\Delta T_{\text {ad }}$. Figure 2 combines results from two direct probes and from indirect (magnetic and calorimetric (differential scanning calorimetry, DSC)) techniques. Such an extensive characterization has only recently been published for G-MCE materials, ${ }^{[24]}$ but is crucial in order to obtain a reliable picture of the thermomagnetic behavior around a FOT. The specific-heat curves of $\mathrm{MnFe}_{0.95} \mathrm{P}_{0.595} \mathrm{~B}_{0.075} \mathrm{Si}_{0.33}$ can be found in the Supporting Information. The latent heat obtained by the integration of the curve in zero field is $L=3.8 \mathrm{~kJ} \mathrm{~kg}^{-1}$. This significantly lower value than for materials without $B$ ( $L=12.3 \mathrm{~kJ} \mathrm{~kg}^{-1}$ for $\mathrm{MnFe}_{0.95} \mathrm{P}_{2 / 3} \mathrm{Si}_{1 / 3}$ and $L=6.4 \mathrm{~kJ} \mathrm{~kg}^{-1}$ for $\left.\mathrm{Mn}_{1.25} \mathrm{Fe}_{0.7} \mathrm{P}_{1 / 2} \mathrm{Si}_{1 / 2}\right)$ is assumed to be at least partially the reason for the larger $\mathrm{dT}_{\mathrm{C}} / \mathrm{d} B=4.3(2) \mathrm{K} \mathrm{T}^{-1}$ found in $\mathrm{MnFe}_{0.95} \mathrm{P}_{0.595} \mathrm{~B}_{0}$ ${ }_{.075} \mathrm{Si}_{0.33}$ than the 3.5(2) $\mathrm{K} \mathrm{T}^{-1}$ found in $\mathrm{Mn}_{1.25} \mathrm{Fe}_{0.7} \mathrm{P}_{1 / 2} \mathrm{Si}_{1 / 2}{ }^{[21]}$ From a metrological point of view, special care has been paid to avoid miscalculations that could result in a "spike" on the $\Delta S(T)$ curves. ${ }^{[25-27]}$ Moreover, since both the hysteresis and the width of the FOT are limited in the present compound, one can expect this problem to be very minor.

The $\Delta S(T)$ curves derived from isofield magnetic measurements and calorimetry upon heating, Figure $2 \mathrm{a}$, are in good agreement: $\Delta S^{\max }=9.1(8) \mathrm{J} \mathrm{kg}^{-1} \mathrm{~K}^{-1}$ at $279.1 \mathrm{~K}$ by DSC and $\Delta S^{\max }=9.8 \pm 1.0 \mathrm{~J} \mathrm{~kg}^{-1} \mathrm{~K}^{-1}$ at $281 \mathrm{~K}$ by the magnetic method. These values are much higher than those of the archetypical MCE material Gd. ${ }^{[1,2]}$ Compared with G-MCE materials, $\Delta S$ of $\mathrm{MnFe}(\mathrm{P}, \mathrm{Si}, \mathrm{B})$ is similar to that of $\mathrm{Gd}_{5} \mathrm{Si}_{2} \mathrm{Ge}_{2}$, higher than the values generally found in Heusler alloys, and just below the best performances found for $\mathrm{La}(\mathrm{Fe}, \mathrm{Si}){ }_{13} \mathrm{H}_{\mathrm{y}^{\circ}}{ }^{[1,2]}$ However, it should be kept in mind that the indirect $\Delta S$ measurements we are referring to do not disclose the reversibility of the MCE, a point for which direct measurements, in particular of $\Delta T_{\text {ad }}$, are more suitable.

We used two types of direct methods to measure the adiabatic temperature change (denoted as $\Delta T_{\text {cyclic }}$ hereafter). The first direct measurements were carried out in a device using a 

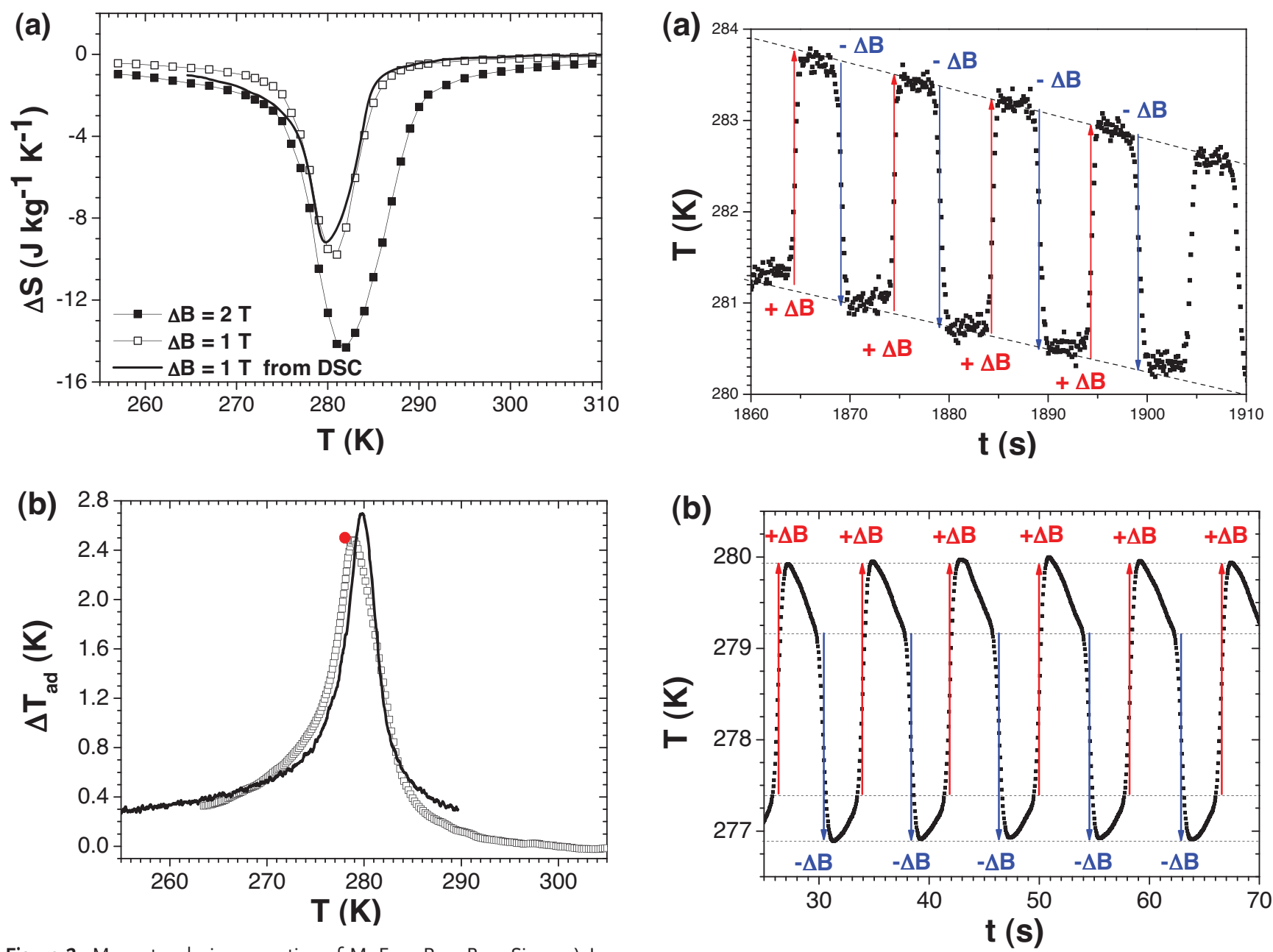

Figure 2. Magnetocaloric properties of $\mathrm{MnFe}_{0.95} \mathrm{P}_{0.595} \mathrm{~B}_{0.075} \mathrm{Si}_{0.33}$. a) Isothermal entropy changes as a function of the temperature derived from calorimetric (DSC) measurements $(\Delta B=1 \mathrm{~T}$, solid line) and from mag. netic measurements ( $\Delta B=1 \mathrm{~T}$, open squares; $\Delta B=2 \mathrm{~T}$, filled squares). b) Temperature dependence of the adiabatic temperature changes derived from DSC measurements for $\Delta B=1 \mathrm{~T}$ (open squares) and from direct methods: in sweep mode $\Delta B=1.1 \mathrm{~T}$ (solid line) and using constant starting temperatures for $\Delta B=1 \mathrm{~T}$ (filled circle).

continuous sweep of the temperature during field oscillations $(\Delta B=1.1 \mathrm{~T})$. Figure 3a presents a typical raw-data curve. Application and removal of the magnetic field creates a tower shape response overlaying a linear temperature versus time evolution, which corresponds to the sweep rate of the measurement. The same values $\Delta T_{\text {cyclic }}=2.8 \mathrm{~K}$ are obtained irrespectively of the direction of the magnetic-field change, which is a first indication of total reversibility of the MCE in this material. To avoid any inconsistencies that may result from the dynamic character of this measurement, especially when dealing with a material still displaying a small thermal hysteresis, a second kind of direct $\Delta T_{\text {cyclic }}$ measurement was performed. Instead of being swept, the external temperature was maintained in such a way that the same starting temperatures before each field application and removal were used. In this case, the resulting temperature versus time profile, Figure $3 \mathrm{~b}$, simulates a Brayton magnetic-refrigeration cycle. ${ }^{[1,2]}$ Therefore, this cyclic measurement

Figure 3. Temperature versus time signals of direct $\Delta T_{\text {cyclic }}$ measurements in $\mathrm{MnFe}_{0.95} \mathrm{P}_{0.595} \mathrm{~B}_{0.075} \mathrm{Si}_{0.33}$. a) In sweep mode for $\Delta B=1.1 \mathrm{~T}$. b) At constant starting temperatures for $\Delta B=1 \mathrm{~T}$. In both cases, the dashed lines indicate the start/end temperatures of the magnetic cycles. The arrows mark $\Delta T_{\text {cyclic }}$.

directly reflects the material performance for applications. For $\Delta B=1 \mathrm{~T}$, a $\Delta T_{\text {cyclic }}$ of $2.55 \mathrm{~K}$ is achieved and maintained during all subsequent cycles. These two direct $\Delta T_{\text {cyclic }}$ measurements are finally compared with the indirect calorimetric method (DSC) in Figure 2b. One observes good agreement of the adiabatic temperature changes, the values derived from $\Delta T_{\text {cyclic }}$ in sweeping mode are slightly higher $(2.8 \mathrm{~K})$ since this corresponds to a field change of $1.1 \mathrm{~T}$.

Compared to the best materials, $\Delta T_{\text {ad }}$ of $\mathrm{MnFe}_{0.95} \mathrm{P}_{0.595} \mathrm{~B}_{0.075} \mathrm{Si}_{0.33}$ is similar to that of $\mathrm{Gd}$ and most of the G-MCE compounds. ${ }^{[1,2]}$ For instance, the present performances are close to the "giant $\Delta T_{\text {ad }}$ " reported in Heusler alloys $\left(\Delta T_{\text {ad }}=2.8 \mathrm{~K}\right.$ at $1 \mathrm{~T}$ for $\left.\mathrm{Ni}_{45.2} \mathrm{Mn}_{36.7} \mathrm{In}_{13} \mathrm{Co}_{5.1}\right) \cdot{ }^{[16]}$ However, in sharp contrast with this latter example, where only a small part of $\Delta T_{\text {ad }}$ is reversible, the large MCE presently observed is fully reversible when the field is cycled, which is an overwhelming advantage of $\mathrm{MnFe}(\mathrm{P}, \mathrm{Si}, \mathrm{B})$ compounds. These new materials are also a significant improvement over the previous $\mathrm{MnFe}(\mathrm{P}, \mathrm{Si})$ generation, since the same $\Delta S$ values are observed while $\Delta T_{\text {ad }}$ 
has been enhanced by more than $30 \%$. This enhancement of $\Delta T_{\text {ad }}$ at intermediate magnetic fields is ascribed to the larger $\mathrm{d} T_{\mathrm{C}} / \mathrm{d} B$, so indirectly comes from the higher magnetization and lower latent heat of this new material.

The last progress achieved for $\mathrm{MnFe}(\mathrm{P}, \mathrm{Si}, \mathrm{B})$ materials concerns the mechanical stability. This problem, already noticed in G-MCE materials, manifests itself by, for instance, the degradation of $\Delta T_{\mathrm{ad}}$ during cyclic measurements. ${ }^{[18]}$ Qualitatively, we observe that bulk pieces of $\mathrm{MnFe}_{0.95} \mathrm{P}_{0.595} \mathrm{~B}_{0.075} \mathrm{Si}_{0.33}$ do not show any degradation when cycled across the transition. Quantitatively, even after 10000 cycles of magnetization/demagnetization used in the $\Delta T_{\text {cyclic }}$ measurements, the sample geometry remains intact and the mechanical integrity is maintained while the MCE does not show any degradation (Supporting Information S3). We believe that this improved mechanical stability in comparison with $\mathrm{MnFe}(\mathrm{P}, \mathrm{Si})$ compounds or other G-MCE materials is partially related to the absence of a cellvolume change at the transition. In $\mathrm{MnFe}_{0.95} \mathrm{P}_{0.595} \mathrm{~B}_{0.075} \mathrm{Si}_{0.33}$, the jump of the $c / a$ ratio at $T_{\mathrm{C}}$ is almost as pronounced as in $\mathrm{Mn}_{1.25} \mathrm{Fe}_{0.7} \mathrm{P}_{0.5} \mathrm{Si}_{0.5},{ }^{[21]}$ but no discontinuous volume change is observed within the experimental accuracy, Figure 4. This exceptionally small $\Delta V$ turns out to be smaller than in all other $\operatorname{MnFe}(\mathrm{P}, x)$ compounds, for instance smaller than in As-based materials (where $\Delta V / V=-0.44 \%$ ), ${ }^{[28]}$ in Ge-based materials (where $\Delta V / V=+0.1 \%$ ), ${ }^{[29]}$ and in Si-based materials. ${ }^{[21]}$

Generally speaking, the present study highlights that, besides magnetism, the key parameter to be controlled in the design of promising G-MCE materials is the latent heat of the FOT. More precisely, $L$ has to be large enough to ensure high $\Delta S$ values but
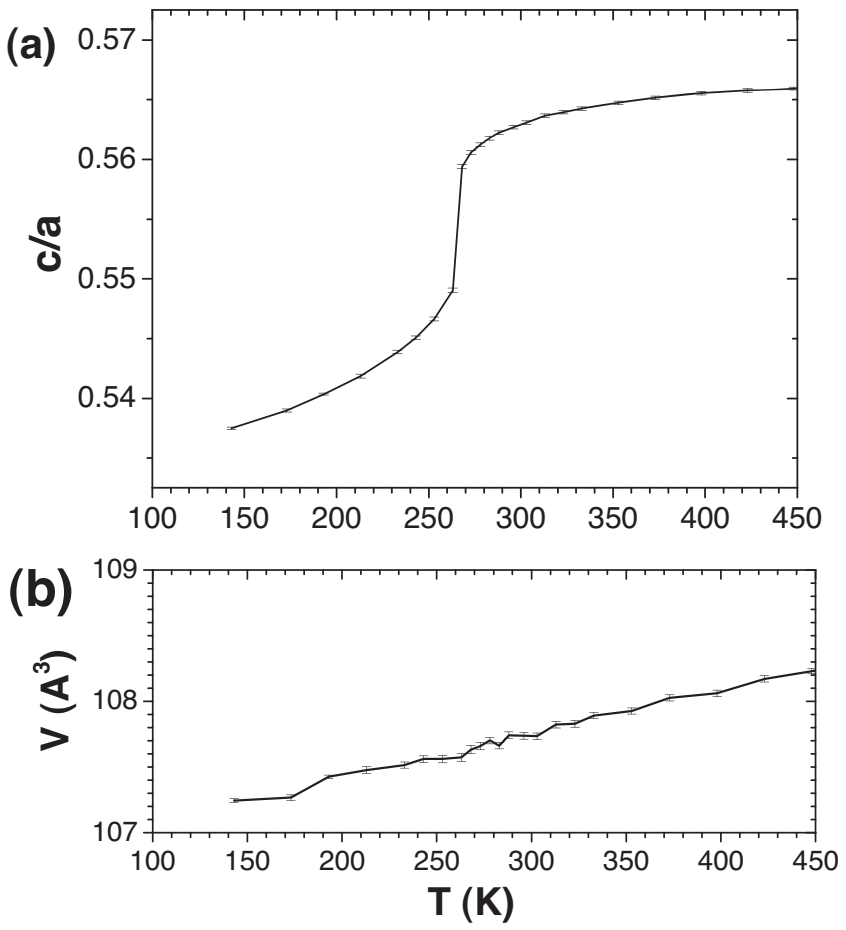

Figure 4. Temperature evolution of the cell parameters of $\mathrm{MnFe}_{0.95} \mathrm{P}_{0.595} \mathrm{~B}_{0.075} \mathrm{Si}_{0.33}$. a) Ratio $c / a$ of the lattice parameters derived from X-ray diffraction patterns measured at different temperatures. b) Temperature dependence of the cell volume. should be "kept under control" to maintain a large $\mathrm{d} T_{\mathrm{C}} / \mathrm{d} B$ and $\Delta T_{\text {ad }}$. Regarding the $\operatorname{MnFe}(\mathrm{P}, x) \mathrm{MCE}$ family, it is found that $\mathrm{B}$ substitution has a similar effect as in $\mathrm{Fe}_{2} \mathrm{P}$, a point which was not straightforward at first glance since we are actually dealing with FOTs about 50 times stronger than in $\mathrm{Fe}_{2} \mathrm{P}$. From an application point of view, the combination of a tunable $T_{\mathrm{C}}(\mathrm{Mn} / \mathrm{Fe}$, $\mathrm{P} / \mathrm{Si}$, and $\mathrm{B}$ composition parameters), no toxic or critical elements, high $\Delta S$, high $\Delta T_{\mathrm{ad}}$, total reversibility of the effect, and good mechanical stability gives $\mathrm{MnFe}(\mathrm{P}, \mathrm{Si}, \mathrm{B})$ compounds considerable advantages, making them highly promising for magnetic refrigeration. Compared to $\mathrm{La}(\mathrm{Fe}, \mathrm{Si})_{13}$ hydrides, it is still unclear which material has the largest reversible MCE but, in any case, these new $\mathrm{MnFe}(\mathrm{P}, \mathrm{Si}, \mathrm{B})$ materials neither contain a rare-earth element nor suffer from dehydrogenation.

\section{Experimental Section}

The parent and B-substituted samples were prepared in the same way. Stoichiometric quantities of $\mathrm{Mn}$ flakes, $\mathrm{Fe}_{2} \mathrm{P}, \mathrm{B}$, and $\mathrm{Si}$ powders were ground in a planetary ball mill for $10 \mathrm{~h}$. The resulting powders were pressed into pellets and sealed in quartz ampules under 200 mbar of Ar. Double-step sintering was performed according to the process already described. ${ }^{[2]]}$ The samples were cycled 5 times across the FOT prior to any measurements. The structural parameters were studied by collecting $X$-ray diffraction patterns at various temperatures in a PANalytical X'Pert PRO diffractometer equipped with an Anton Paar TTK450 lowtemperature chamber. The magnetization measurements were carried out in a magnetometer equipped with a superconducting quantum interference device (SQUID; Quantum Design MPMS 5 XL with reciprocating sample option, RSO). The isofield magnetization curves $M_{B}(T)$ were measured in sweeping mode at a rate of $1 \mathrm{~K} \mathrm{~min}^{-1}$ with a temperature increment of $0.5 \mathrm{~K}$. For the $\Delta S$ derivation on the basis of magnetic data and the use of the Maxwell equation, ${ }^{[1,2]} M_{B}(T)$ curves were recorded with a field increment of $0.25 \mathrm{~T}$. The DSC measurements were performed in a Peltier cell calorimeter described previously, ${ }^{[30]}$ from which calorimetric $\Delta S$ and $\Delta T_{\text {ad }}$ were derived by means of the usual methods. ${ }^{[2]}$ The direct $\Delta T_{\text {cyclic }}$ measurements with temperature sweeping, Figure $3 \mathrm{a}$, were carried out in a homemade device, for which the temperature versus time signal was recorded by a thermocouple clamped between two slices of sample (cylindrical shape of $10 \mathrm{~mm}$ diameter and $1 \mathrm{~mm}$ thickness). External-magnetic-field changes were applied by moving/removing the samples from the magnetic field at a rate of $1.1 \mathrm{~T} \mathrm{~s}^{-1}$. The direct $\Delta T_{\text {cyclic }}$ measurements of Figure $3 \mathrm{~b}$ were carried out on a cubic sample of $60 \mathrm{mg}$ with the probe described in the literature. ${ }^{[31]}$

\section{Supporting Information}

Supporting Information is available from the Wiley Online Library or from the author.

\section{Acknowledgements}

The authors thank A. J. E. Lefering and R. Siertsema for their technical help and F. R. de Boer for his comments. This work is part of an Industrial Partnership Program of the Dutch Foundation for Fundamental Research on Matter (FOM), co-financed by BASF New Business. Thanks are also due to Fondazione Angelo Della Riccia for the financial support given to G. Porcari between January and June 2013.

Received: September 24, 2013

Revised: January 7, 2014

Published online: February 22, 2014 
[1] K. A. Gschneidner, Jr., V. K Pecharsky, A. O. Tsokol, Rep. Prog. Phys. 2005, 68, 1479.

[2] A. Smith, C. R. H. Bahl, R. Bjørk, K. Engelbrecht, K. K. Nielsen, N. Pryds, Adv. Energy Mater. 2012, 2, 1288.

[3] V. K. Pecharsky, K. A. Gschneidner, Jr., Phys. Rev. Lett. 1997, 78, 4494.

[4] K. A. Gschneidner Jr., Y. Mudryk, V. K. Pecharsky, Scr. Mater. 2012, $67,572$.

[5] H. Wada, Y. Tanabe, Appl. Phys. Lett. 2001, 79, 3302.

[6] F. X. Hu, B.-G. Shen, J.-R. Sun, Z. Cheng, G. Rao, X. Zhang, Appl. Phys. Lett. 2001, 78, 3675.

[7] A. Fujita, S. Fujieda, Y. Hasegawa, K. Fukamichi, Phys. Rev. B 2003 67, 104416

[8] O. Tegus, E. Brück, K. H. J. Buschow, F. R. de Boer, Nature 2002, 415, 150.

[9] N. T. Trung, Z. Q. Ou, T. J. Gortenmulder, O. Tegus, K. H. J. Buschow, E. Brück, Appl. Phys. Lett. 2009, 94, 102513.

[10] D. T. Cam Thanh, E. Brück, N. T. Trung, J. C. P. Klaasse, K. H. J. Buschow, Z. Q. Ou, O. Tegus, L. Caron, J. Appl. Phys. 2008, 103, $07 \mathrm{~B} 318$.

[11] N. H. Dung, Z. Q. Ou, L. Caron, L. Zhang, D. T. Cam Thanh, G. A. de Wijs, R. A. de Groot, K. H. J. Buschow, E. Brück, Adv. Energy Mater. 2011, 1, 1215.

[12] F.-X. Hu, B.-G. Shen, J.-R. Sun, G.-H. Wu, Phys. Rev. B 2001, 64, 132412.

[13] T. Krenke, E. Duman, M. Acet, E. F. Wassermann, X. Moya, L. Mañosa, A. Planes, Nat. Mater. 2005, 4, 450.

[14] R. Kainuma, Y. Imano, W. Ito, Y. Sutou, H. Morito, S. Okamoto, O. Kitakami, K. Oikawa, A. Fujita, T. Kanomata, K. Ishida, Nature 2006, 439, 957.

[15] A. Planes, L. Mañosa, M. Acet, J. Phys.: Condens. Matter 2009, 21, 233201.
[16] J. Liu, T. Gottschall, K. P. Skokov, J. D. Moore, O. Gutfleisch, Nat. Mater. 2012, 11, 620

[17] N. T. Trung, L. Zhang, L. Caron, K. H. J. Buschow, E. Brück, Appl. Phys. Lett. 2010, 96, 172504.

[18] J. Lyubina, R. Schäfer, N. Martin, L. Schultz, O. Gutfleisch, Adv Mater. 2010, 22, 3735.

[19] O. Beckman, L. Lundgren, P. Nordblad, P. Svedlindh, A. Törne, Y. Andersson, S. Rundqvist, Phys. Scr. 1982, 25, 679.

[20] H. Yamada, K. Terao, Phase Transitions 2002, 75, 231.

[21] N. H. Dung, L. Zhang, Z. Q. Ou, L. Zhao, L. van Eijck, A. M. Mulders, M. Avdeev, E. Suard, N. H. van Dijk, E. Brück, Phys. Rev. B 2012, 86, 045134

[22] Z. Q. Ou, L. Zhang, N. H. Dung, L. van Eijck, A. M. Mulders, M. Avdeev, N. H. van Dijk, E. Brück, J. Magn. Magn. Mater. 2013, $340,80$.

[23] R. Chandra, S. Bjarman, T. Ericsson, L. Häggström, C. Wilkinson, R. Wäppling, Y. Andersson, S. Rundqvist, J. Solid State Chem. 1980, $34,389$.

[24] K. Morrison, K. G. Sandeman, L. F. Cohen, C. P. Sasso, V. Basso, A. Barcza, M. Katter, J. D. Moore, K. P. Skokov, O. Gutfleisch, Int. J. Refrig. 2012, 35, 1528.

[25] G. J. Liu, J. R. Sun, J. Shen, B. Gao, H. W. Zhang, F. X. Hu, B. G. Shen, Appl. Phys. Lett. 2007, 90, 032507.

[26] L. Tocado, E. Palacios, R. Burriel, J. Appl. Phys. 2009, 105, 093918.

[27] S. Das, J. S. Amaral, V. S. Amaral, J. Appl. Phys. 2010, 107, 09 A912.

[28] K. Koyama, T. Kanomata, K. Watanabe, Jpn. J. Appl. Phys. 2005, 44, 549.

[29] H. Yabuta, K. Umeo, T. Takabatake, K. Koyama, K. Watanabe, J. Phys. Soc. Jpn. 2006, 75, 113707.

[30] G. Porcari, F. Cugini, S. Fabbrici, C. Pernechele, F. Albertini, M. Buzzi, M. Mangia, M. Solzi, Phys. Rev. B 2012, 86, 104432.

[31] G. Porcari, M. Buzzi, F. Cugini, R. Pellicelli, C. Pernechele, L. Caron, E. Brück, M. Solzi, Rev. Sci. Instrum. 2013, 84, 073907. 